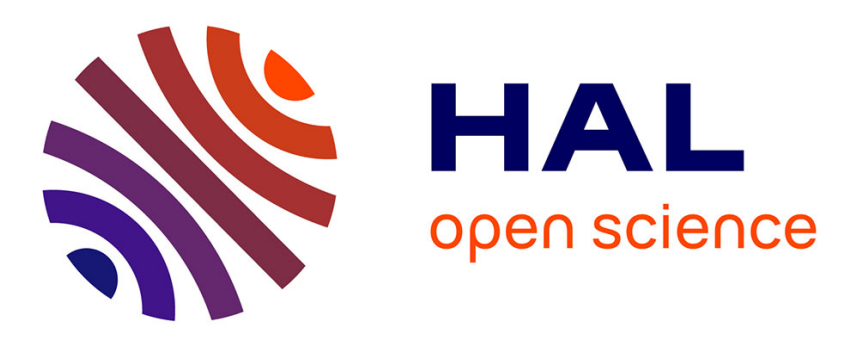

\title{
The partitioning of radiated energy and the largest aftershock of seismic sequences occurred in the northeastern Italy and western Slovenia
}

Stefania Gentili, Gianni Bressan

\section{- To cite this version:}

Stefania Gentili, Gianni Bressan. The partitioning of radiated energy and the largest aftershock of seismic sequences occurred in the northeastern Italy and western Slovenia. Journal of Seismology, 2008, Volume 12, Number 3, 343-354,, 12 (3), pp.343-354. 10.1007/s10950-007-9075-x . hal-00646232

HAL Id: hal-00646232

https://hal.inria.fr/hal-00646232

Submitted on 29 Nov 2011

HAL is a multi-disciplinary open access archive for the deposit and dissemination of scientific research documents, whether they are published or not. The documents may come from teaching and research institutions in France or abroad, or from public or private research centers.
L'archive ouverte pluridisciplinaire HAL, est destinée au dépôt et à la diffusion de documents scientifiques de niveau recherche, publiés ou non, émanant des établissements d'enseignement et de recherche français ou étrangers, des laboratoires publics ou privés. 
J Seismol (2008) 12:343-354 DOI 10.1007/s10950-007-9075-x

The original publication is available at:

http://www.springerlink.com/content/q39j661819340r24/

\section{THE PARTITIONING OF RADIATED ENERGY AND THE LARGEST AFTERSHOCK OF SEISMIC SEQUENCES OCCURRED IN THE NORTHEASTERN ITALY AND WESTERN SLOVENIA}

S. Gentili and G. Bressan

\section{ABSTRACT}

We analyzed the most relevant seismic sequences occurred from 1977 to 2007 in the FriuliVenezia Giulia region (northeastern Italy) and western Slovenia. The 8 aftershock sequences were triggered by low to moderate magnitude earthquakes with mainshock duration magnitude ranging from 3.7 to 5.6. The $b$-value of the Gutenberg-Richter law varies from 0.8 to 1.1. The modified Omori's modeling of the sequences evidences values of the $p$ exponent ranging from 0.8 to 1.0. Using the Reasenberg and Jones $(1989,1994)$ approach, we computed the probabilistic estimate of the aftershock rates and the largest aftershock in given time intervals. The difference in magnitude between the mainshock and the largest aftershock is calculated according to the modified Båth law and using an approach that considers the partitioning of the radiated seismic energy between mainshock and aftershocks. The partitioning of the radiated seismic energy appears to play a significant role in the evolution of the sequences. We define the parameter $R_{\mathrm{ES}}$ as the ratio between the radiated seismic energy of the mainshock and the summation of the seismic energy radiated by the aftershocks. The difference in magnitude between the mainshock and the largest aftershock, calculated with the parameter $\mathrm{R}_{\mathrm{ES}}$, agrees well with the observed difference. In most sequences, the parameter $\mathrm{R}_{\mathrm{ES}}$ decreases very quickly till the occurrence of the largest aftershock and then becomes constant. By analyzing the values of $\mathrm{R}_{\mathrm{ES}}$ during the early hours following the mainshock, we found that the $R_{E S}$ values after 24 hours are well related to the final ones, calculated on the whole sequence, and to the differences in magnitude between the mainshock and the largest aftershock. 


\section{INTRODUCTION}

The understanding of the space-time evolution and the magnitude distribution of the aftershock sequences has been the goal of several investigations because of its strong implications for earthquake nucleation and seismic hazard analysis. Some investigations were mainly devoted to the study of the triggering mechanism of the aftershocks and the physical properties of the rocks where mainshocks occur (Scholz, 1968; Yamashita and Knopoff, 1987; Kisslinger and Jones, 1991; Dieterich, 1994; Marcellini, 1995; Correig et al., 1997; Miller et al., 2004). The forecasting of the behavior of the aftershock sequences has been the main purpose of other investigations (Kagan and Knopoff, 1981; Ogata, 1988; Reasenberg and Jones, 1989; Gerstenberger et al., 2005). In particular, some studies were devoted to the estimation of the largest aftershock (Shcherbakov and Turcotte, 2004) and to the probabilistic techniques (Reasenberg and Jones 1989, 1994) for forecasting the number of aftershocks and the probability to have an aftershock with magnitude larger than the mainshock magnitude minus one.

This study is mainly focussed on estimating the largest aftershock by the analysis of the most relevant sequences occurred in the Friuli-Venezia Giulia region (northeastern Italy) and in western Slovenia, from 1977 to 2007 (Franceschina et al., 2006; Gentili and Bressan, 2007), recorded by the local seismic network of the Istituto Nazionale di Oceanografia e Geofisica Sperimentale (OGS), that started to operate from May 7, 1977. The seismic sequences were triggered by low to moderate magnitude main events with $\mathrm{M}_{\mathrm{D}}$ ranging from 3.7 to 5.6. We apply the technique of Reasenberg and Jones $(1989,1994)$ for the estimation of aftershock rates and largest aftershocks probability and we test the applicability of the modified form of Båth law formulated by Shcherbakov and Turcotte (2004).

Shcherbakov and Turcotte research involves the partitioning of the radiated seismic energy during a mainshock-aftershock sequence. Bressan et al. (2007) found that the mechanism of stress release of the mainshock can influence the partitioning of the radiated seismic energy between mainshock and aftershocks. In this paper, we analyze the aspects related to the partitioning of the radiated seismic energy, in particular, how it is influenced by the strongest aftershock and how it varies in the early hours following the mainshock. The seismic sequences were located with the HYPO71 program (Lee and Lahr, 1975). The average horizontal error is $0.9 \mathrm{~km}$. The values of magnitude are given in duration magnitude $\mathrm{M}_{\mathrm{D}}$, computed according to Rebez and Renner (1991). 


\section{AFTERSHOCK SEQUENCES: MAIN FEATURES}

The aftershock sequences (Tab.1) were triggered by the following mainshocks: the September 16, 1977 Trasaghis earthquake with $\mathrm{M}_{\mathrm{D}} 5.2$ (T77); the February 1, 1988 Mena earthquake with $\mathrm{M}_{\mathrm{D}} 4.1$ (M88); the October 5, 1991 Tarcento earthquake with $\mathrm{M}_{\mathrm{D}} 3.8$ (Tar91); the April 20, 1994 Claut earthquake with $\mathrm{M}_{\mathrm{D}} 3.7$ (C94); the April 13, 1996 Claut earthquake with $\mathrm{M}_{\mathrm{D}}$ 4.3 (C96); the April 12, 1998 Kobarid earthquake with $\mathrm{M}_{\mathrm{D}} 5.6$ (K98); the February 14, $2002 \mathrm{M}$. Sernio earthquake with $\mathrm{M}_{\mathrm{D}} 4.9$ (S02) and the July 12, 2004 Kobarid earthquake with $\mathrm{M}_{\mathrm{D}} 5.1$ (K04). Fig. 1a, b, c shows the epicenters of the sequences. Generally, the sequences are spatially clustered and well separated in space and time without overlapping.

The aftershocks have been selected by defining simple space and time windows for each sequence. The earthquake rate has been calculated on a 30 days sliding time window with one day step for increasing circular areas centered on the epicenter of the mainshock. For each area, the aftershock sequence was assumed ended when the rate became constant for at least 6 months time. In this way, a sequence duration $T(R)$ was defined, depending on the radius $R$ of the area. The circular area including the whole sequence was selected as the one for which the rate of seismicity did not vary with increasing radius. We did not adopt here the standard method that defines the duration of the aftershock sequence as the time required for the seismicity rate to decrease to the value before the mainshock, because seismic quiescences, each lasting different period, were recognized before the occurrence of the sequences (Gentili and Bressan, 2007).

The use of circular areas for selecting the spatial extent of the aftershocks appears questionable. The spatial pattern of the aftershocks is related to the redistribution of local stresses following the mainshock faulting. King et al. (1994), Stein et al. (1994) and many others demonstrated that the aftershocks are concentrated in regions of Coulomb stress increase. In some cases, involving strike-slip faulting, the aftershock distribution appears to delineate the mainshock fault plane (Reasenberg and Ellsworth, 1982), in other cases the aftershocks occur in the peripheral region of the coseismic slip (Mendoza and Hartzell, 1988). A diffuse pattern, without a clear fault plane, seems to be characteristic of thrust faulting (Cisternas et al., 1982; Ekström et al., 1992; Hauksson et al., 1995). However this feature was observed also in the case of aftershocks triggered by normal mainshock faulting (Richins et al., 1987). So, even if it is a crude approximation, we chose circular area as the simplest way for selecting the aftershocks.

The radius of the circular area affected by the aftershocks and the temporal duration of each sequence are reported in Tab. 1, together with the average horizontal location error for each sequence. Fig. $2 a$ and $2 b$ show the relations between the $M_{D}$ of the mainshock and the radius and between the $\mathrm{M}_{\mathrm{D}}$ of the mainshock and the temporal duration of the aftershocks, that we obtained by 
fitting our data. The parameters of the regression are also shown. The regressions have been obtained by a nonlinear least squares fit by using the inverse of the error on the dependent variable as weight for each datum.

The frequency-magnitude scaling of Gutenberg and Richter (1954) states that:

$$
\log _{10}\left(N\left(M_{c}\right)\right)=A-b M_{c}
$$

where $N\left(M_{c}\right)$ is the number of earthquakes with magnitude larger than $M_{c}, A$ is a measure of the regional level of seismicity (Kagan 2004), while $b$ depends on the proportion of large and small earthquakes (Gerstenberger et al, 2005).

The parameters $A, b$ and the completeness magnitude $M_{\min }$ have been evaluated for each sequence by the Zmap software (Wiemer 2001). In particular, the $b$-value was obtained by the maximum likelihood estimation, using the Utsu (1978) formulation:

$$
b=\frac{1}{\log _{10}\left[\bar{M}-\left(M_{\min }-\Delta M / 2\right)\right]}
$$

where $\bar{M}$ is the mean magnitude considered and $\Delta M$ is the magnitude resolution; the completeness magnitude has been evaluated by the Entire Magnitude Range method (EMR) (J. Woessner and S. Wiemer 2005); the parameter $A$ has been estimated as:

$A=\log _{10}\left(N_{T}\right)+b M_{\text {min }}$

where $N_{T}$ is the total number of earthquakes with magnitude greater than $M_{\min }$. The errors on the parameters have been evaluated by the bootstrapping techniques of Efron and Tibshirani (1993). The results are summarized in Tab. 2 .

The aftershock temporal decay can be described by the Utsu's (1961) modified Omori law, that relates the rate of aftershocks with magnitude larger than $M_{c}$ to a function of time $t$ elapsed after the main shock:

$\lambda\left(t, M_{c}\right)=\frac{K\left(M_{c}\right)}{(t+c)^{p}}$

where $K\left(M_{c}\right)$ is related to the total number of earthquakes, $c$ depends on the rate of activity in the earliest part of the sequence and $p$ is related to the temporal decay of the aftershocks (Kisslinger and Jones, 1991). Also these parameters have been calculated by the software Zmap, that finds the maximum likelihood estimates of the parameters, setting $M_{c}=M_{\min }$, i.e. using all the earthquakes with magnitude greater than the magnitude of completeness. The standard deviation of the parameters has been taken as the error on the measure. The results are shown in Tab. 2, together with the mean and the weighted average of the parameters $A, b, c$ and $p$. This information is not supplied for $K$ since, as it is shown in equation (5), it depends on $M_{c}$ that changes from one 
sequence to the other because the completeness magnitude is different. The other parameters are assumed to be independent of $M_{c}$.

Some authors found a dependence of $c$ on $M_{c}$ (Shcherbakov et al. 2004). It should be noted that just immediately after the mainshock it is likely that weak earthquakes are missed due to overlapping on the seismograms. This may cause an overestimating of $c$ (Utsu et al. 1995) and a dependence on $M_{c}$ (Utsu 2002b). Some authors supposed that the true value of $c$ is zero or negative and that positive values are artifacts due to the loose of the first aftershocks (Kagan 2004, Kagan and Houston, 2005). However, Yamakawa (1968) and Vidale et al. (2003), investigating on accurately selected data, found that the level of aftershock activity is less than that predicted one if $c$ is 0 or negative. A detailed description of the problem can be found in Utsu et al. (1995). To avoid problems connected with the lack of data, Zmap software allows to estimate $c$ considering the sequence some time after the mainshock. In this paper, we used a time shift of 0.2 days. Because of the low values of $c$ and of the larger corresponding errors for most sequences (see Table 2), the existence or not of a dependence on $M_{c}$ can not be deduced.

The error of the parameters of C94, S02 and Tar91 sequences presented in Table 2 is high, because of the small number of aftershock in the sequence (30 or less). The range of $p$ values is 0.8-1.0, falling within the range (0.6-1.55) of well documented sequences quoted by Utsu et al. (1995).

\section{PROBABILISTIC ESTIMATE OF THE AFTERSHOCK RATE AND} STRONG AFTERSHOCKS

In this section we apply the forecasting method of the sequence behavior of Reasenberg and Jones (1989, 1994). Reasenberg and Jones proposed the following aftershock occurrence model, that describes the rate of aftershocks with magnitude larger than $M_{c}$ as a function of time and of the main shock magnitude:

$\lambda\left(t, M_{c}\right)=\frac{10^{a+b\left(M_{m}-M_{c}\right)}}{(t+c)^{p}}$

where $M_{m}$ is the magnitude of the main shock, $a$ is the "productivity" (Gasperini and Lolli, 2006), $c$ and $p$ are the parameters of the modified Omori law (eq. 4) and $b$ is the parameter of equation (1).

Lolli and Gasperini (2003) used this approach to develop nomograms for expeditious prediction of aftershock occurrence in Italy, by analizing 30 sequences with local magnitude ranging from 4.3 to 6.5 , occurred from 1960 to 1996 . They reported the equations for the evaluation of the number of aftershocks above the magnitude $M_{c}$ in the time interval $[S, T]$ : 


$$
N\left(M_{c}\right)=\int_{S}^{T} \lambda\left(t, M_{c}\right) d t
$$

and the equation of Reasenberg and Jones (1994) that calculates the probability of occurrence of one or more shocks above the magnitude $M_{c}$ in a time interval $\Delta T$ following the time $T$ (assuming a random occurrence of earthquakes - Poissonian distribution):

$$
\operatorname{Pr}\left(T, \Delta T, M_{c}\right)=1-\exp \left[-\int_{T}^{T+\Delta T} \lambda\left(t, M_{c}\right) d t\right]
$$

Using equation (6), Lolli and Gasperini (2003) plotted the number of expected aftershock in a 24-hour-long interval following the time elapsed from the mainshock for different magnitude thresholds. The same number is plotted also for different seismic areas in Italy, setting the magnitude threshold to $M_{m}$-2. In addition, using equation (7), they calculated the probability of a strong aftershock (with $M \geq M_{D m^{-}}$) for different intervals of time following the time elapsed from the mainshock. The same curves of probability are plotted also for different seismic areas in Italy fixing the interval of time at 7 days.

In this section, we perform the same analysis using our data. Since we use duration magnitude, while Lolli and Gasperini (2003) used local magnitude, we converted the difference of duration magnitude into difference of local magnitude to compare the results. The relation between $\mathrm{M}_{\mathrm{D}}$ and local magnitude, according to Franceschina et al. (2006), is :

$M_{L}=1.2 M_{D}-0.73$

We obtain:

$$
\Delta M_{L}=1.2 \Delta M_{D}
$$

i.e. 1.2 steps in local magnitude corresponds to 1 step in duration magnitude.

The parameter $a$ is obtained from $K\left(M_{\min }\right)$, using the equation:

$$
a=\log _{10}\left(K\left(M_{\text {min }}\right)\right)-b\left(M_{m}-M_{\text {min }}\right)
$$

The obtained data are summarized in Table 2, together with their mean value and their weighted average. For computing equations (6) and (7) we used the weighted average of the parameters of Table 2 because the relative errors of the parameters of some sequences are high, due to the small number of earthquakes involved.

The number of expected aftershocks in a 24-hour-long interval following the time elapsed from the mainshock, for different duration magnitude thresholds, is plotted in Fig. 3. The probability of a strong aftershock (with $M \geq M_{D m^{-}}$1), for different temporal intervals following the time elapsed from the mainshock, is plotted in Fig. 4. The parameters shown in table 2 and those 
found by Lolli and Gasperini (2003) for a different set of sequences in Friuli Venezia Giulia Italian region are comparable.

Furthermore, we investigated the limits of the previous analysis. Fig. 5 e.g. shows the theoretical number of expected earthquakes in a 24-hour-long interval following the time elapsed from the mainshock, for magnitude greater or equal to $M_{m}-3$. This is compared with the real observed numbers for the four sequences for which $M_{m i n} \leq M_{m}-3$. The plot is semi-logarithmic, in order to handle zero values.

While K08 and K04 sequences are close to the curve, the number of real aftershocks is smaller for T77 and S02, especially in the first day. This depends mainly on the fluctuations of the value of the parameter $b$ of the Gutenberg-Richter equation, from one sequence to the other. In fact, the rate of the earthquakes (see equation 5) scales as $10^{b\left(M_{m}-M_{c}\right)}$ and, e.g. , for $M_{m}-M_{c}=3$ a $0.3 b$ fluctuation leads to a factor 8 in the earthquakes rate.

\section{THE LARGEST AFTERSHOCK AND THE BÅTH LAW}

The Båth law (Båth 1965) states that the difference in magnitude $\Delta m$ between the mainshock and the largest aftershock of a sequence is a constant, independent on the mainshock magnitude, typically about 1.2. Shcherbakov and Turcotte (2004) analyzed 10 large earthquakes occurred in California between 1987 and 2003, with magnitude equal to or greater than 5.5 and found that the mean value of $\Delta m$ was 1.16 with a standard deviation 0.46 .

Shcherbakov and Turcotte (2004) proposed a modified form of the Bath's law from an extrapolation of the Gutenberg - Richter (G-R) frequency magnitude scaling (equation 1). Considering only the magnitude $M^{*}$ of the largest aftershock they obtained from equation (1) the so called "modified Båth law":

$M^{*}=\frac{A}{b}$

Substitution of equation (11) in (1) gives:

$\log _{10}\left[N\left(M \geq M_{c}\right)\right]=b\left(M_{m}-\Delta m^{*}-M_{c}\right)$

where $\Delta m^{*}=M_{m}-M^{*}$.

Shcherbakov and Turcotte (2004) analyzed also the partitioning of the released seismic energy between mainshock and aftershocks and its relation to $\Delta m^{*}$. They used the following relation between energy and magnitude:

$\log _{10} E(M)=\alpha M+\log _{10} E_{0}$

where $\alpha$ and $E_{0}$ are constants and $M$ is the magnitude. In particular they use the moment magnitude and set $\alpha=3 / 2$ and $E_{0}=6.3 * 10^{\wedge} 4 \mathrm{~J}$, according to Utsu (2002a). 
They found the following relation:

$\frac{E_{a s}}{E_{m s}}=\frac{b}{\alpha-b} 10^{-\alpha \Delta m^{*}}$

where $E_{a s}$ is the total radiated energy of the aftershocks, $E_{m s}$ is the radiated energy of the mainshock and $b$ is the constant of the G-R frequency-magnitude scaling.

We applied the Shcherbakov and Turcotte (2004) method to the sequences here considered. The mainshock released seismic energy of K98, K04, S02, C96, C94 has been taken from Bressan et al. (2007) and Franceschina (1996). The one of T77 has been taken from Suhadolc (1981). The estimate of seismic energy of the other earthquakes have been calculated using the relation between the seismic energy and the duration magnitude of Bressan et al. (2007):

$\log _{10} E=1.94 M_{D}+2.26 \quad \sigma\left(\log _{10} E\right)=0.52$

The constant $\alpha$ of the equation (13) is therefore, using $M_{D}, 1.94$.

We tested the Båth law, the modified Båth law and equation (14) on our data (see Table 3). The observed values of $\Delta m$ appear to be not consistent with the Båth approximation. The mean and the standard deviation of the difference between $\Delta m^{*}$ obtained applying the Båth law (named $\Delta m_{B}^{*}$ in Tab.3) and the observed $\Delta m$ values are 0.25 and 0.49 , respectively. The values of magnitude difference obtained with the modified Båth law (equation (12) - named $\Delta m_{M B}^{*}$ in Tab.3), differ in some cases from the observed $\Delta m$. The mean and the standard deviation of the difference between $\Delta m_{M B}^{*}$ and $\Delta m$ are -0.02 and 0.24 , respectively. On the contrary, the values of magnitude difference obtained applying equation (14) (named $\Delta m_{S T}^{*}$ in Tab.3), that accounts for the partitioning of energy between mainshock and aftershocks and for the $b$ value, agree quite well with the observed $\Delta m$ values. The mean and the standard deviation of the difference between $\Delta m_{S T}^{*}$ and $\Delta m$ are -0.06 and 0.09 , respectively.

\section{THE PARTITIONING OF ENERGY}

According to Scholz (1990), the aftershocks result from the stress transfer following the mainshock and they are considered a secondary process caused by the residual stresses remaining after the mainshock rupture. This suggests that the stress released by the mainshock can influence the partition of the radiated seismic energy between mainshock and aftershocks.

Bressan et al. (2007) investigated the stress release mechanism of some of the seismic sequences considered in the present paper, by analyzing the earthquake source parameters. They found that the best correlated source parameter of the mainshock with the partition of radiated seismic energy between mainshock and aftershocks is the Brune stress drop, a source parameter that 
measures the stress released. The Brune stress drop of the mainshock appears to increase with the ratio $\left(\mathrm{R}_{\mathrm{ES}}\right)$ between the seismic energy radiated by the mainshock and the summation of the seismic energies radiated by the aftershocks. Fig 6 shows the $R_{E S}$ values versus the Brune stress drop for some of the sequences here analyzed. The cases shown regard only the Brune stress drop values directly estimated by spectral analysis (Bressan et al. 2007, Franceschina 1996).

It should be noted that $\mathrm{R}_{\mathrm{ES}}$ is just the inverse of the parameter that Shcherbakov and Turcotte (2004) consider in their equation 12 (eq. 14 in this paper). To explore this aspect, we calculated the ratio $R_{E S}$ for the sequences here analyzed. As shown in Table 4, the ratio of the radiated energy in mainshock to the radiated energy in aftershocks, is not constant. We rearrange the equation (14) in order to obtain a relation between of $\Delta m^{*}$ and $R_{E S}$ :

$$
\Delta m^{*}=-\frac{1}{\alpha} \log _{10}\left(\frac{E_{a s}}{E_{m s}}\right)-\frac{1}{\alpha} \log _{10}\left(\frac{\alpha-b}{b}\right)=\frac{1}{\alpha} \log _{10}\left(R_{E S}\right)+\frac{1}{\alpha} \log _{10}\left(\frac{b}{\alpha-b}\right)
$$

where $R_{E S}=E_{m s} / E_{a s}$. In this equation the value of $\Delta m^{*}$ depends on two terms: the first accounts for the energy ratio $R_{E S}$ and the second accounts for $b$. The first term contribution on the analyzed sequences ranges from 0.34 to 1.67 . The second term contribution ranges from -0.08 to 0.06 . So, assuming that the last term can be considered negligible, equation (16) can be written in the following form:

$$
\Delta m^{*}=\frac{1}{\alpha} \log _{10}\left(R_{E S}\right)
$$

Table 4 shows the values of $R_{E S}$ and the magnitude difference evaluated using equation (17) (named $\Delta m_{R E S}^{*}$ ). The results agree quite well with the observed values of $\Delta m$. The mean and the standard deviation of the difference between $\Delta m_{R E S}^{*}$ and $\Delta m$ are -0.04 and 0.07 , respectively, similar to the results obtained with the equation (14) of Shcherbakov and Turcotte (2004). The fraction of the radiated energy of the aftershocks to the total radiated energy varies from $0.05 \%$ (S02 sequence) to about 16\% (M88 sequence), with an average value of about 4\%. Fig. 7 shows the value of $R_{E S}$ of each sequence as a function of time elapsed from the mainshock. In most cases the $\mathrm{R}_{\mathrm{ES}}$ parameter decreases very quickly till the occurrence of the largest aftershock and then becomes constant.

Of course, it would be extremely important to forecast the evolution of the aftershock sequences starting from the early hours following the mainshock. We calculated the value of $\mathrm{R}_{\mathrm{ES}}$ of each sequence at $6,12,24$ hours after the occurrence of the mainshock versus the final value of $R_{E S}$ $\left(\mathrm{R}_{\mathrm{ES}} \mathrm{T}\right)$. The $\mathrm{R}_{\mathrm{ES}}$ values at 24 hours appear less scattered and best related to the final $\mathrm{R}_{\mathrm{ES}}$ (the coefficient of determination $R^{2}$ at $6,12,24$ hours are $0.71,0.66$ and 0.81 , respectively). Fig. 8 shows the value of $R_{E S}$ of each sequence calculated at 24 hours versus the final value of $R_{E S}\left(R_{E S} T\right)$. We 
recall that at this time, the largest aftershock has already occurred only in the Tar91 sequence.The analyzed cases show that the partitioning of radiated seismic energy, already in the early hours after the occurrence of the mainshock, is characterized by a trend comparable with that final one. We point out that the choice of 24 hours is arbitrary and based on practical convenience.

In Fig. 9 we plot $\Delta m$ as a function of the $\mathrm{R}_{\mathrm{ES}}$ of each sequence calculated 24 hours after the main shock - $\mathrm{R}_{\mathrm{ES}}(24)$. The equation obtained by the regression of the data in Fig. 9 is the following:

$$
\Delta m=0.4 \log _{10}\left(R_{E S}(24)\right)-0.1
$$

The magnitude difference between the mainshock and the largest aftershock (named $\Delta m_{R E S 24}^{*}$ ), obtained from $\mathrm{R}_{\mathrm{ES}}(24)$ values, is shown in table 4. The mean and the standard deviation of the difference between $\Delta m_{R E S 24}^{*}$ and the observed ones are 0.02 and 0.22 , respectively, similar to those calculated by the modified Båth law.

\section{CONCLUSIONS}

The eight most relevant sequences occurred from 1977 to 2007 in the Friuli-Venezia Giulia region (northeastern Italy) and western Slovenia are analyzed. The aftershock sequences were triggered by low-moderate magnitude events, with mainshock $\mathrm{M}_{\mathrm{D}}$ ranging from 3.7 to 5.6. The sequences were essentially characterized by a dominant mainshock followed by smaller magnitude aftershocks. Among the aftershocks, one largest event is recognizable. The difference in magnitude between the mainshock and the largest aftershock ranges from 0.4 to 1.7 . The $b$-value of the Gutenberg-Richter law is found ranging from 0.8 to 1.1 . The $p$ parameter of the modified Omori law, that accounts for the aftershock temporal decay, varies from 0.8 to 1.0 .

The Reasenberg and Jones $(1989,1994)$ forecasting method of the sequences behaviour was applied to the sequences analyzed. We calculated the number of expected aftershocks in a 24-hourlong interval, following the time elapsed from the mainshock, for different magnitude thresholds. The probability curves of a strong aftershock, with $M \geq M_{m}-1$, for different intervals of time following the time elapsed from the mainshock were also elaborated. The results obtained and those of Lolli and Gasperini (2003), on a different set of sequences in the same area, are comparable.

The difference in magnitude between the mainshock and the largest aftershock was calculated according to the Shcherbakov and Turcotte (2004) approach. The mean and the standard deviation of the difference between $\Delta m_{M B}^{*}$ obtained with their modified Båth law and $\Delta m$ are 0.02 and 0.24 , respectively. The value $\Delta m_{S T}^{*}$ obtained with the relation that takes into account the partitioning of the radiated seismic energy between mainshock and aftershocks and the Gutenberg- 
Richter parameter $b$ agrees quite well with the observed $\Delta m$. In particular, the mean and the standard deviation of the difference between $\Delta m_{S T}^{*}$ and $\Delta m$ are -0.06 and 0.09 , respectively.

The partitioning of the radiated seismic energy between mainshock and aftershocks appears to play a significant role in the evolution of the sequences. Bressan et al. (2007) defined the parameter $\mathrm{R}_{\mathrm{ES}}$ as the ratio between the radiated seismic energy of the mainshock to the summation of the seismic energy radiated by the aftershocks. We show that the difference in magnitude $\Delta m_{R E S}^{*}$ between the mainshock and the largest aftershock, calculated with the parameter $\mathrm{R}_{\mathrm{ES}}$, agrees quite well with the observed difference $\Delta m$. In particular, the mean and the standard deviation of the difference between $\Delta m_{R E S}^{*}$ and $\Delta m$ are -0.04 and 0.07, respectively. Following Shcherbakov and Turcotte (2004), if we assume that all earthquakes of each sequence have the same seismic efficiency (ratio of the radiated seismic energy to the total energy released), then $R_{E S}$ is the ratio of the total energy released by the mainshock to the total energy released by the aftershocks. In most cases, the $\mathrm{R}_{\mathrm{ES}}$ parameter decreases very quickly in time till the occurrence of the largest aftershock and then becomes nearly constant. Analyzing the values of $\mathrm{R}_{\mathrm{ES}}$ during the early hours following the mainshock, we obtained a relation between the $\mathrm{R}_{\mathrm{ES}}$ calculated 24 hours after the mainshock and $\Delta m$. The mean and the standard deviation of the difference between the values of $\Delta m_{R E S}^{*}$ calculated by our relation and the observed ones are 0.02 and 0.22 , respectively, similar to the ones calculated by the modified Båth law.

Even if the obtained results seem promising we point out the limits of the investigation. The analysis is restricted to 8 aftershock sequences, triggered by low to moderate magnitude events, all characterized by the largest aftershock with magnitude lesser than the mainshock. The correlations obtained are worth further investigation and at present the results cannot be generalized as a typical behavior mainshock-aftershock sequence.

\section{ACKNOWLEDGMENTS}

We would like to thank Pier Luigi Bragato for his valuable discussions and suggestions. This study was performed with the contribution of the Istituto Nazionale di Geofisica e Vulcanologia and the Italian Civil Protection in the framework of the project "Real- and quasi realtime ground motion estimates of significant earthquakes in the Italian region" (contract S4/03). The local seismic network is managed by the Dip. Centro di Ricerche Sismologiche of Istituto Nazionale di Oceanografia e Geofisica Sperimentale (OGS) with the financial contribution of the Regione Friuli-Venezia Giulia. We thank the technical staff for data acquisition. 


\section{REFERENCES}

Båth M (1965) Lateral inomogeneities in the upper mantle. Tectonophysics 2:483-514

Bressan G, Kravanja S, Franceschina G (2007) Source parameters and stress release of seismic sequences occurred in the Friuli-Venezia Giulia region (Northeastern Italy) and in Western Slovenia. Phys Earth Planet Inter 160:192-214

Cisternas A, Dorel J, Gaulon R (1982) Models of the complex source of the El Asnam earthquake. Bull Seismol Soc Am 72:2245-2266

Correig M A, Urquizù H, Vila J, Manrubia SC (1997) Aftershock series of event February 18, 1996: an interpretation in terms of self-organized critically. J Geophys Res 102:27407-27420

Dieterich J (1994) A constitutive law for rate of earthquake production and its application to earthquake clustering. J Geophys Res 99:2601-2618

Efron B, Tibshirani R (1993) An Introduction to the Bootstrap. Monographs on Statistics and Applied Probability 57 Chapman and Hall/CRC, New York, London

Ekström G, Stein R S, Eaton J P, Eberhart-Phillips D (1992) Seismicity and geometry of a 110-km-long blind thrust fault 1. The 1985 Kettleman Hills, California, earthquake. J Geophys Res 97:4843-4864

Franceschina G L (1996) Relazione magnitudo-momento e legge di scala per eventi di bassa magnitudo dell'area friulana. Consiglio Nazionale delle Ricerche Techn Rep CNR-IRRS/MS, 8, Milano

Franceschina G, Kravanja S, Bressan G (2006) Source parameters and scaling relationships in the Friuli-Venezia Giulia (Northeastern Italy) region Phys. Earth Planet. Inter. 154:148-167

Gasperini P, Lolli B (2006) Comparing different models of aftershock rate decay: The role of catalog incompleteness in the first times after main shock. Tectonophysics 423:43-59

Gentili S, Bressan G (2007) Seismicity patterns before $M_{D} \geq 4.1$ earthquakes in the FriuliVenezia Giulia (northeastern Italy) and western Slovenia areas Boll Geof Teor Appl, 48(1):33-51

Gerstenberger M, Wiemer S, Jones L, Reasenberg P A (2005) Real-time Forecasts of Tomorrow's Earthquakes in California Nature 435:328-331

Gutenberg B, C F Ricther (1954) Seismicity of the Earth and associated phoenomena. Princeton Univ. Press, Princeton, New Jersey

Hauksson E, Jones L M, Hutton K (1995) The 1994 Northridge earthquake sequence in California: seismological and tectonic aspects. J Geophys Res 100:12335-12355

Kagan Y Y (2004) Short-term properties of earthquake catalogs and models of earthquake source. Bull Seismol Soc Am 94:12071228 
Kagan Y Y, Houston H (2005) Relation between mainshock rupture process and Omori's law for aftershock moment release rate. Geophys J Int 163:1039-1048.

Kagan Y Y, Knopoff L (1981). Stochastic synthesis of earthquake catalogs. J Geophys Res 89: $2853-2862$

King G C P, Stein R S, Lin J (1994) Static stress changes and the triggering of earthquakes. Bull Seismol Soc Am 84:935-953

Kisslinger C, Jones L M (1991) Properties of aftershock sequences in Southern California. J Geophys Res 96:11947-11958

Lee W H K, Lahr J C (1975) HYPO71 (revised); a computer program for determining hypocenter, magnitude and first motion pattern of local earthquakes. U.S. Geol Surv Open-File Rept, 75-311, 113 pp.

Lolli B, Gasperini P (2003) Aftershock hazard in Italy Part I: Estimation of time-magnitude distribution model parameters and computation of probabilities of occurrence. J Seismol 7:235-257

Marcellini A (1995) Arrhenius behavior of aftershock sequences. J Geophys Res 100:64636468

Mendoza C, Hartzell S H (1988) Aftershock patterns and main shock faulting. Bull Seismol Soc Am 78:1438-1449

Miller A S, Collettini C, Chairaluce L, Cocco M, Barchi M, Kaus B J P (2004) Aftershock driven by a high-pressure $\mathrm{CO}_{2}$ source at depth. Nature 27:724-727

Ogata Y (1988) Statistical models for earthquake occurrences and residual analysis for point processes. J Am Stat Assoc 83:9-27

Reasemberg P, Ellsworth W L (1982) Aftershocks of the Coyote lake, California, earthquake of August 6, 1979: a detailed study. Bull Seismol Soc Am 87:10637-10655

Reasenberg P A, Jones L M (1989) Earthquake hazard after the mainshock in California. Science 243:1173-1176.

Reasenberg P A, Jones LM (1994) Earthquake aftershocks: Update. Science 265:12511252.

Rebez A, Renner G (1991) Duration magnitude for the northeastern Italy seismometric network. Boll Geof Teor Appl 33:177-186

Richins W D, Pechmann J C, Smith R B, Langer C J, Goter S K, Zollweg J E, King J J (1987) The Borah Peak Idaho, earthquake and its aftershocks. Bull Seismol Soc Am 77:694-723

Scholz C H (1968) Microfractures, aftershocks and seismicity. Bull Seismol Soc Am 58:1117-1130 
Scholz C H (1990) The mechanics of earthquakes and faulting. Cambridge University Press, Cambridge, 439 pp.

Shcherbakov R, Turcotte D L (2004) A Modified Form of Bath's law. Bull Seismol Soc Am 94(5):1968-1975

Shcherbakov R, Turcotte D L, Rundle J B (2004) A generalized Omori's law for earthquake aftershock decay. Geophys. Res. Lett. 31 L11613 doi:10.1029/2004GL019808

Stein R S, King G C P, Lin J (1994) Stress triggering of the 1994 M = 6.7 Northridge, California, earthquake by its predecessors. Science 265:1432-1435

Suhadolc P (1981) Spatial distribution of the aftershock sequence relative to the September 16, 1977 Friuli earthquake. Boll Geof Teor Appl 92:331-348

Utsu T (1961) A statistical study on the occurrence of aftershocks. Geophys Mag 30:521605

Utsu T (1978) Estimation of parameter values in the formula for the magnitude-frequency relation of earthquake occurrence, Zisin (J Seism Soc Japan) 31:367-382

Utsu T (2002a) Relationships between magnitude scales, International Handbook of Earthquake and Engineering Seismology. In: William H.K. Lee, Hiroo Kanamori, Paul Jennings, Carl Kisslinger (eds) Part A, Academic press, Amsterdam, 733-746

Utsu T (2002b) Statistical Features of seismicity in: Lee W, Kanamori H, Jennings P, Kisslinger P (eds) (2002) International Handbook of Earthquake and Engineering Seismology, Part A. Academic Press, London. 719-732

Utsu T, Ogata Y, Matsu'ura R S (1995) The centenary of the Omori formula for a decay law of aftershock activity. J Phys Earth 43:1-33

Vidale J E, Cochrau E S, Kanamori H, Clayton R W (2003) After the lightning and before the thunder: non-Omori behavior of early aftershocks?. EOS Trans. AGU 84, Fall Meeting Suppl., Abstract S31A-08

Wiemer S (2001) A software package to analyze seismicity: ZMAP. Seism Res Let 72(2):373-382

Woessner J, Wiemer S (2005) Assessing the Quality of Earthquake Catalogues: Estimating the Magnitude of Completeness and Its Uncertainty. Bull Seismol Soc Am 95(2):684-698

Yamakawa N (1968) Foreshocks, aftershocks and earthquake swarms (IV) - Frequency decrease of after shocks in its initial and later stages. Pap. Met. Geophys. 19:109-119

Yamashita T, Knopoff L (1987) Model of aftershock occurrence. Geophys. J R Astron Soc 91:13-26 


\section{FIGURE CAPTIONS}

Fig. 1: Map of the earthquake sequences: (a) Circles: the 1994 Claut sequence (C94); triangles: the 1977 Trasaghis sequence (T77); diamonds: the 1991 Tarcento sequence (Tar91). UD: Udine town; PN: Pordenone town; TS: Trieste town. The inset shows the location of the study area. Longitude-degrees (horizontal axis), latitude-degrees (vertical axis). (b) Circles: the 1988 Mena sequence (M88); triangles: the 1996 Claut sequence (C96); diamonds: the 1998 Kobarid sequence (K98). (c) Circles: the M. Sernio sequence (S02); diamonds: the 2004 Kobarid sequence (K04).

Fig. 2: (a) Sequences radius as a function of the mainshock duration magnitude. (b) The duration of the sequences as a function of the mainshock duration magnitude.

Fig. 3: Number of expected aftershock in the following day as a function of time elapsed from the mainshock, for different magnitude thresholds.

Fig. 4: Probability of a strong aftershock (with $M \geq M_{m}-1$ ) as a function of time after the mainshock.

Fig 5: Number of expected aftershock in the following day as a function of time elapsed from the mainshock, for magnitude greater or equal to $M_{m}-3$, compared with the real observed number for the sequences K98, T77, K04 and S02.

Fig. 6: $R_{E S}$ values versus Brune stress drop $(\Delta \sigma)$ for some of the sequences here analyzed. The cases shown regard only the Brune stress drop estimates by spectral analysis.

Fig. 7: $R_{E S}$ as a function of time for the analyzed sequences. The black dots indicate the occurrence of the largest aftershock of each sequence.

Fig. 8: Final value of $\mathrm{R}_{\mathrm{ES}}\left(\mathrm{R}_{\mathrm{ES}} \mathrm{T}\right)$ of each sequence as a function of its value after 24 hours from the mainshock.

Fig. 9: $\Delta m$ as a function of $\mathrm{R}_{\mathrm{ES}}$ calculated at 24 hours after the occurrence of the mainshock 


\section{TABLE CAPTIONS}

Table 1: Main characteristics of the analyzed sequences. $M_{D m}$ : duration magnitude of the mainshock; Lat and Lon: north latitude and east longitude of the main shock (degrees); $M_{\text {Dmaft }}$ : duration magnitude of the strongest aftershock; $E r_{h}$ : average horizontal location error; $N_{\text {aft }}$ : total number of the aftershocks with magnitude greater or equal to the completeness magnitude.

Table 2: Parameters of the analyzed sequences: $M_{\min }$ : completeness magnitude, $A$ and $b$ : parameters of the Gutenberg Richter law, $K, c$ (days) and $p$ : parameters of the Utsu's (1961) modified Omori law, $a$ : parameter of the Reasenberg and Jones's law (1989).

Table 3: Evaluation of the largest aftershock magnitude using Båth (1965) and Shcherbakov and Turcotte (2004) approaches. $M_{D m}$ : duration magnitude of the mainshock; $M_{D m a f t}$ : duration magnitude of the strongest aftershock; $\Delta m$ : observed difference between the duration magnitude of the mainshock and of the strongest aftershock; $\Delta m_{B}^{*}$ : difference according to the Båth law; $\Delta m_{M B}^{*}$ : calculated difference using modified Båth law; $\Delta m_{S T}^{*}$ calculated difference using equation (14).

Table 4: Evaluation of the largest aftershock magnitude using equations based on $\mathrm{R}_{\mathrm{ES}} \cdot M_{D m}$ : duration magnitude of the mainshock; $M_{\text {Dmaft }}$ d duration magnitude of the strongest aftershock; $\Delta m$ : observed difference between the duration magnitude of the mainshock and of the strongest aftershock; $\Delta m_{R E S}^{*}$ : calculated difference using the final value of $\mathrm{R}_{\mathrm{ES}} ; \Delta m_{R E S 24}^{*}$ : calculated difference using the value of $R_{E S}$ after 24 hours. $R_{E S} T$ : final value of $R_{E S}$. 


\section{TABLES}

\begin{tabular}{|c|c|c|c|c|c|c|c|c|c|c|c|c|}
\hline Seq. & $\mathrm{M}_{\text {Dm }}$ & Lat & Lon & $\begin{array}{c}\text { Date } \mathrm{M}_{\text {Dm }} \\
\mathrm{mm} / \mathrm{dd} / \mathrm{yyyy}\end{array}$ & $\begin{array}{c}\text { time } \\
\mathrm{M}_{\text {Dm }}\end{array}$ & $\mathrm{M}_{\text {Dmaft }}$ & $\begin{array}{c}\text { Date } \mathrm{M}_{\text {Dmaft }} \\
\mathrm{mm} / \mathrm{dd} / \mathrm{yyyy}\end{array}$ & $\begin{array}{c}\text { time } \\
\mathrm{M}_{\text {Dmaft }}\end{array}$ & $\begin{array}{c}\text { Radius } \\
{[\mathrm{km}]}\end{array}$ & $\begin{array}{c}\text { Err }_{\mathrm{h}} \\
{[\mathrm{km}]}\end{array}$ & $\begin{array}{c}\text { Duration } \\
{[\text { days }]}\end{array}$ & $\mathrm{N}_{\text {aft }}$ \\
\hline K98 & 5.6 & 46.324 & 13.678 & $04 / 12 / 1998$ & $10: 55$ & 4.6 & $05 / 06 / 1998$ & $02: 53$ & 18 & 1.1 & 195 & 471 \\
\hline T77 & 5.2 & 46.268 & 13.016 & $09 / 16 / 1977$ & $23: 48$ & 4.0 & $09 / 28 / 1977$ & $01: 43$ & 13 & 1.2 & 138 & 175 \\
\hline K04 & 5.1 & 46.306 & 13.641 & $07 / 12 / 2004$ & $13: 04$ & 3.6 & $07 / 14 / 2004$ & $04: 37$ & 10 & 1.1 & 138 & 166 \\
\hline S02 & 4.9 & 46.439 & 13.107 & $02 / 14 / 2002$ & $03: 18$ & 3.2 & $02 / 25 / 2002$ & $10: 55$ & 10 & 0.7 & 106 & 29 \\
\hline C96 & 4.3 & 46.312 & 12.558 & $04 / 13 / 1996$ & $13: 00$ & 3.5 & $04 / 16 / 1996$ & $18: 06$ & 5 & 0.6 & 70 & 42 \\
\hline M88 & 4.1 & 46.347 & 13.076 & $02 / 01 / 1988$ & $14: 21$ & 3.7 & $02 / 04 / 1988$ & $19: 37$ & 4 & 1.2 & 63 & 123 \\
\hline Tar91 & 3.8 & 46.243 & 13.343 & $10 / 05 / 1991$ & $05: 14$ & 3.4 & $10 / 05 / 1991$ & $14: 56$ & 4 & 0.9 & 54 & 30 \\
\hline C94 & 3.7 & 46.339 & 12.538 & $04 / 20 / 1994$ & $21: 25$ & 3.1 & $04 / 22 / 1994$ & $03: 20$ & 3 & 0.8 & 41 & 15 \\
\hline
\end{tabular}

Table 1

\begin{tabular}{|c|c|c|c|c|c|c|c|}
\hline Seq. & $\mathrm{M}_{\min }$ & $\mathrm{A}$ & $\mathrm{b}$ & $\mathrm{K}\left(\mathrm{M}_{\min }\right)$ & $\mathrm{c}$ & $\mathrm{p}$ & $\mathrm{a}$ \\
\hline $\mathrm{K} 98$ & $2.1 \pm 0.1$ & $5.1 \pm 0.1$ & $1.14 \pm 0.07$ & $38 \pm 3$ & $0.005 \pm 0.006$ & $0.80 \pm 0.02$ & $-2.4 \pm 0.1$ \\
\hline $\mathrm{T} 77$ & $1.2 \pm 0.2$ & $3.2 \pm 0.1$ & $0.85 \pm 0.08$ & $30 \pm 10$ & $0.6 \pm 0.8$ & $1.0 \pm 0.1$ & $-1.9 \pm 0.3$ \\
\hline K04 & $2.0 \pm 0.1$ & $4.4 \pm 0.2$ & $1.1 \pm 0.1$ & $27 \pm 6$ & $0.02 \pm 0.01$ & $1.04 \pm 0.07$ & $-2.0 \pm 0.2$ \\
\hline $\mathrm{S} 02$ & $1.5 \pm 0.2$ & $2.7 \pm 0.3$ & $0.8 \pm 0.2$ & $2 \pm 2$ & $0.00 \pm 0.73$ & $0.8 \pm 0.3$ & $-2.4 \pm 1.0$ \\
\hline C96 & $1.6 \pm 0.2$ & $3.1 \pm 0.3$ & $0.9 \pm 0.2$ & $4.4 \pm 0.8$ & $0.000 \pm 0.004$ & $0.96 \pm 0.08$ & $-1.8 \pm 0.3$ \\
\hline M88 & $1.3 \pm 0.1$ & $3.3 \pm 0.2$ & $0.9 \pm 0.1$ & $18 \pm 7$ & $0.009 \pm 0.406$ & $0.9 \pm 0.1$ & $-1.3 \pm 0.4$ \\
\hline Tar91 & $1.6 \pm 0.2$ & $2.8 \pm 0.3$ & $0.8 \pm 0.1$ & $2.1 \pm 0.6$ & $0.00 \pm 0.02$ & $1.0 \pm 0.2$ & $-1.4 \pm 0.3$ \\
\hline C94 & $1.9 \pm 0.3$ & $3.2 \pm 0.7$ & $1.1 \pm 0.2$ & $3 \pm 6$ & $0.00 \pm 4.06$ & $0.9 \pm 0.7$ & $-1.5 \pm 2.0$ \\
\hline Mean & & $3.5 \pm 0.8$ & $0.9 \pm 0.1$ & & $0.1 \pm 0.2$ & $0.92 \pm 0.09$ & $-1.8 \pm 0.5$ \\
\hline Weighted average & & $3.7 \pm 0.2$ & $1.0 \pm 0.1$ & & $0.01 \pm 0.04$ & $0.9 \pm 0.1$ & $-2.0 \pm 0.2$ \\
\hline
\end{tabular}

Table 2

\begin{tabular}{|c|c|c|c|c|c|c|}
\hline Seq. & $\mathrm{M}_{\text {Dm }}$ & $\mathrm{M}_{\text {Dmaft }}$ & $\Delta m$ & $\Delta m_{B}^{*}$ & $\Delta m_{M B}^{*}$ & $\Delta m_{S T}^{*}$ \\
\hline K98 & 5.6 & 4.6 & 1.0 & 1.2 & 1.1 & 1.0 \\
\hline T77 & 5.2 & 4.0 & 1.2 & 1.2 & 1.4 & 1.1 \\
\hline K04 & 5.1 & 3.6 & 1.5 & 1.2 & 1.0 & 1.4 \\
\hline S02 & 4.9 & 3.2 & 1.7 & 1.2 & 1.5 & 1.6 \\
\hline C96 & 4.3 & 3.5 & 0.8 & 1.2 & 0.9 & 0.7 \\
\hline M88 & 4.1 & 3.7 & 0.4 & 1.2 & 0.6 & 0.4 \\
\hline Tar91 & 3.8 & 3.4 & 0.4 & 1.2 & 0.3 & 0.2 \\
\hline C94 & 3.7 & 3.1 & 0.6 & 1.2 & 0.6 & 0.7 \\
\hline
\end{tabular}

Table 3 


\begin{tabular}{|c|c|c|c|c|c|c|}
\hline Seq. & $\mathrm{M}_{\mathrm{Dm}}$ & $\mathrm{M}_{\text {Dmaft }}$ & $\Delta m$ & $\Delta m_{R E S}^{*}$ & $\Delta m_{R E S 24}^{*}$ & $\mathrm{R}_{\mathrm{ES}} \mathrm{T}$ \\
\hline $\mathrm{K} 98$ & 5.6 & 4.6 & 1.0 & 0.9 & 1.1 & 50.87 \\
\hline $\mathrm{T} 77$ & 5.2 & 4.0 & 1.2 & 1.1 & 1.0 & 159.89 \\
\hline $\mathrm{K} 04$ & 5.1 & 3.6 & 1.5 & 1.4 & 1.3 & 432.79 \\
\hline $\mathrm{S} 02$ & 4.9 & 3.2 & 1.7 & 1.7 & 1.6 & 1745.42 \\
\hline C96 & 4.3 & 3.5 & 0.8 & 0.8 & 1.0 & 31.14 \\
\hline $\mathrm{M} 88$ & 4.1 & 3.7 & 0.4 & 0.4 & 0.7 & 5.289 \\
\hline Tar91 & 3.8 & 3.4 & 0.4 & 0.3 & 0.2 & 4.62 \\
\hline C94 & 3.7 & 3.1 & 0.6 & 0.7 & 0.9 & 21.23 \\
\hline
\end{tabular}

Table 4 


\section{FIGURES}

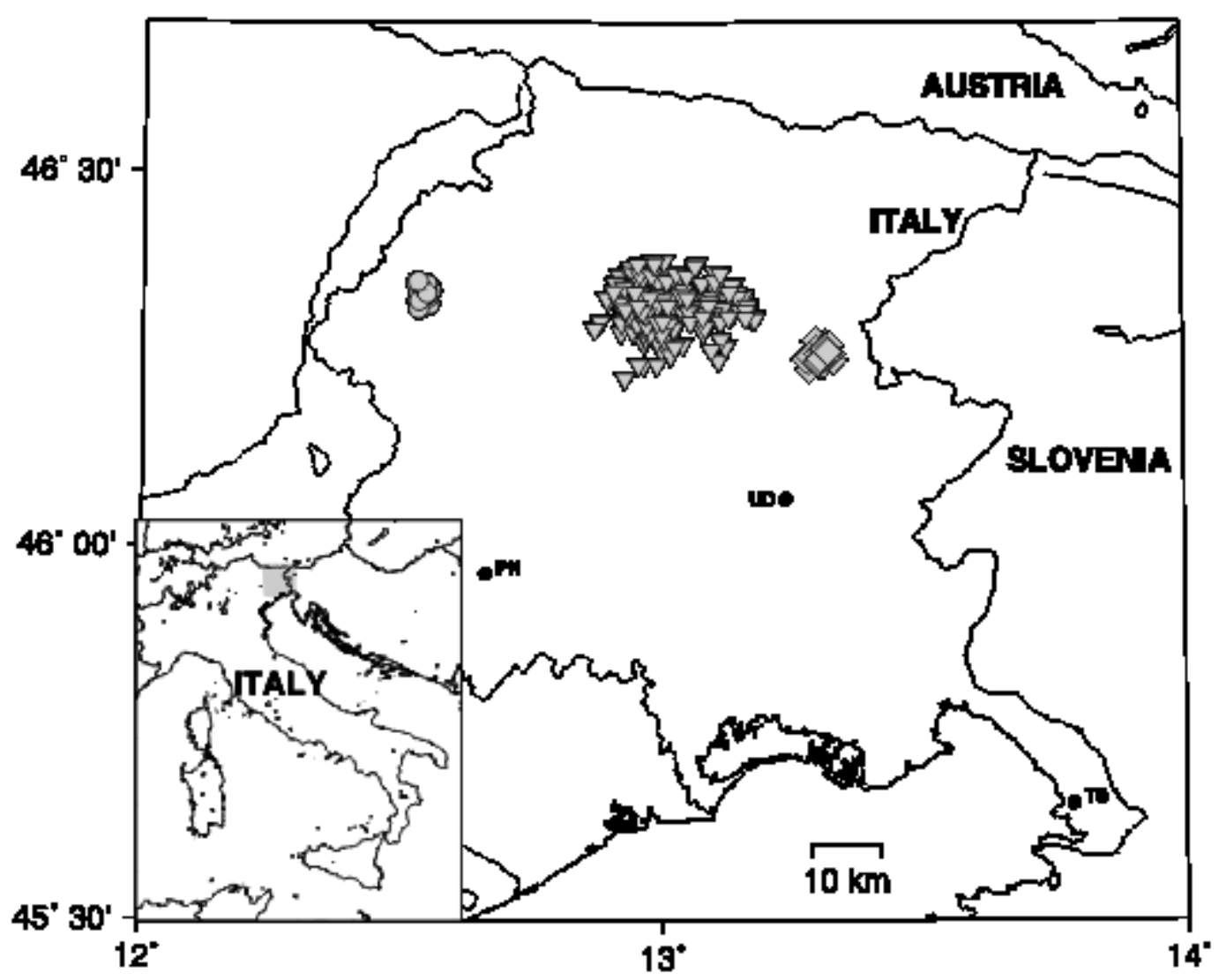

(a) 


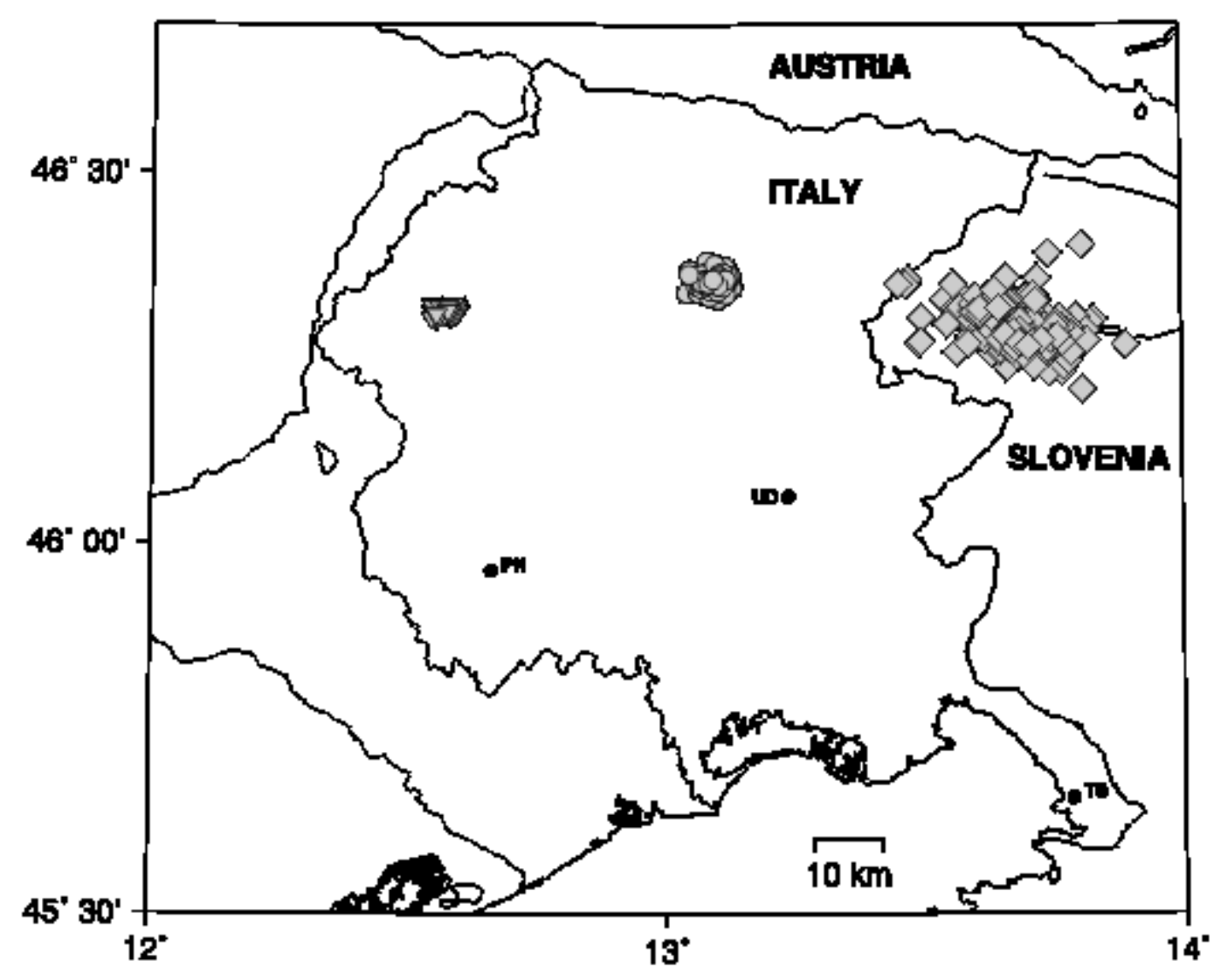

(b) 


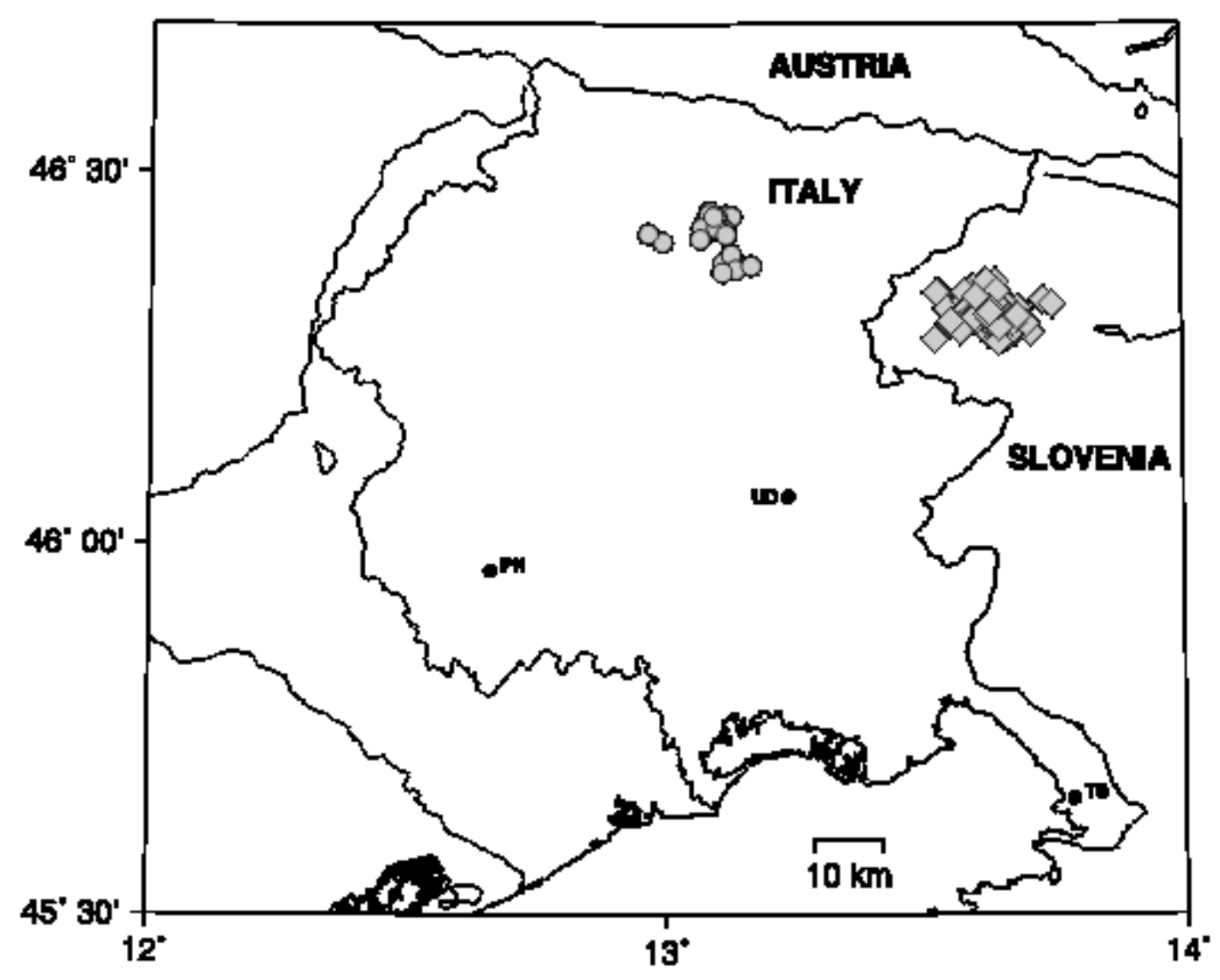

(c)

Fig. 1 


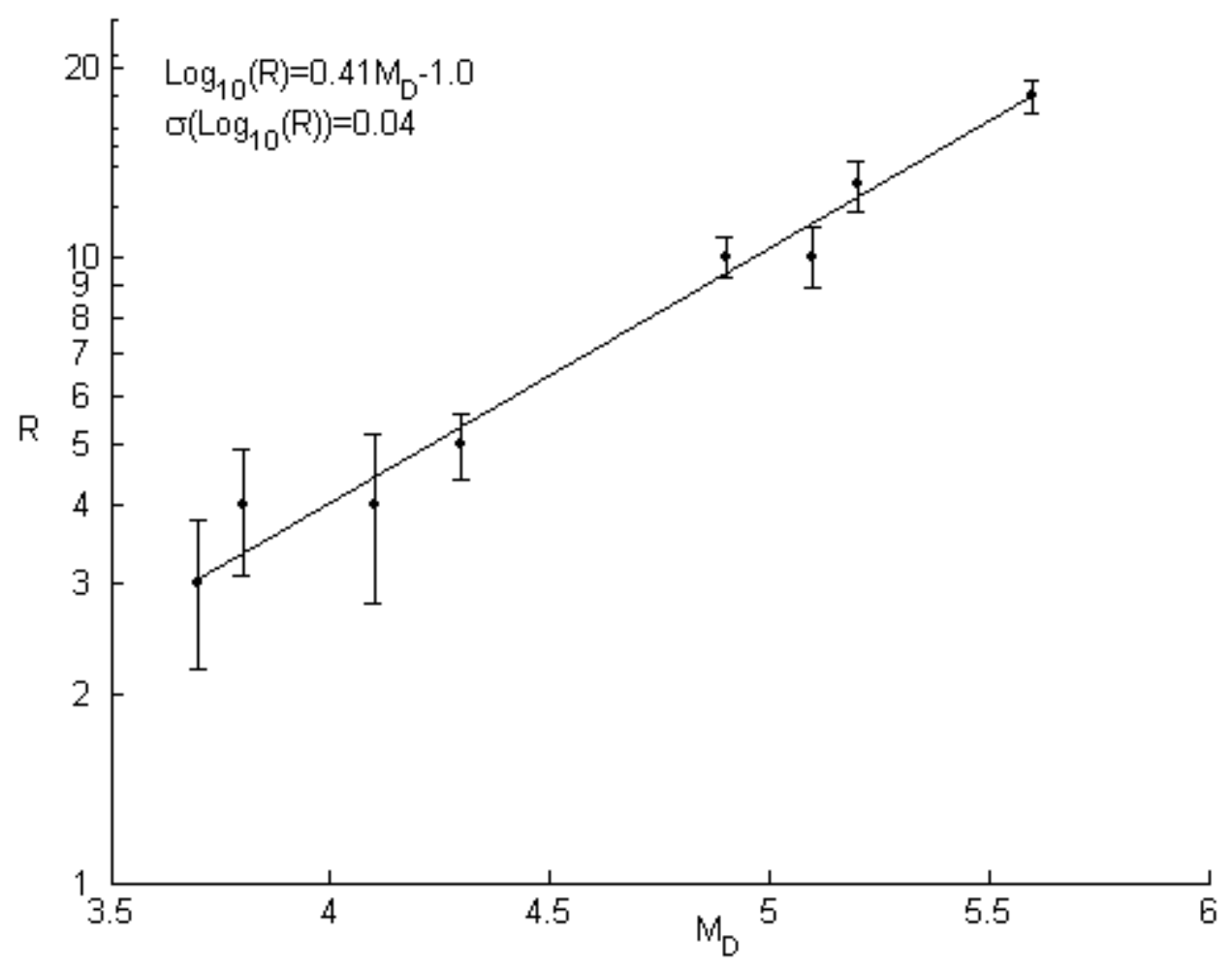

(a)

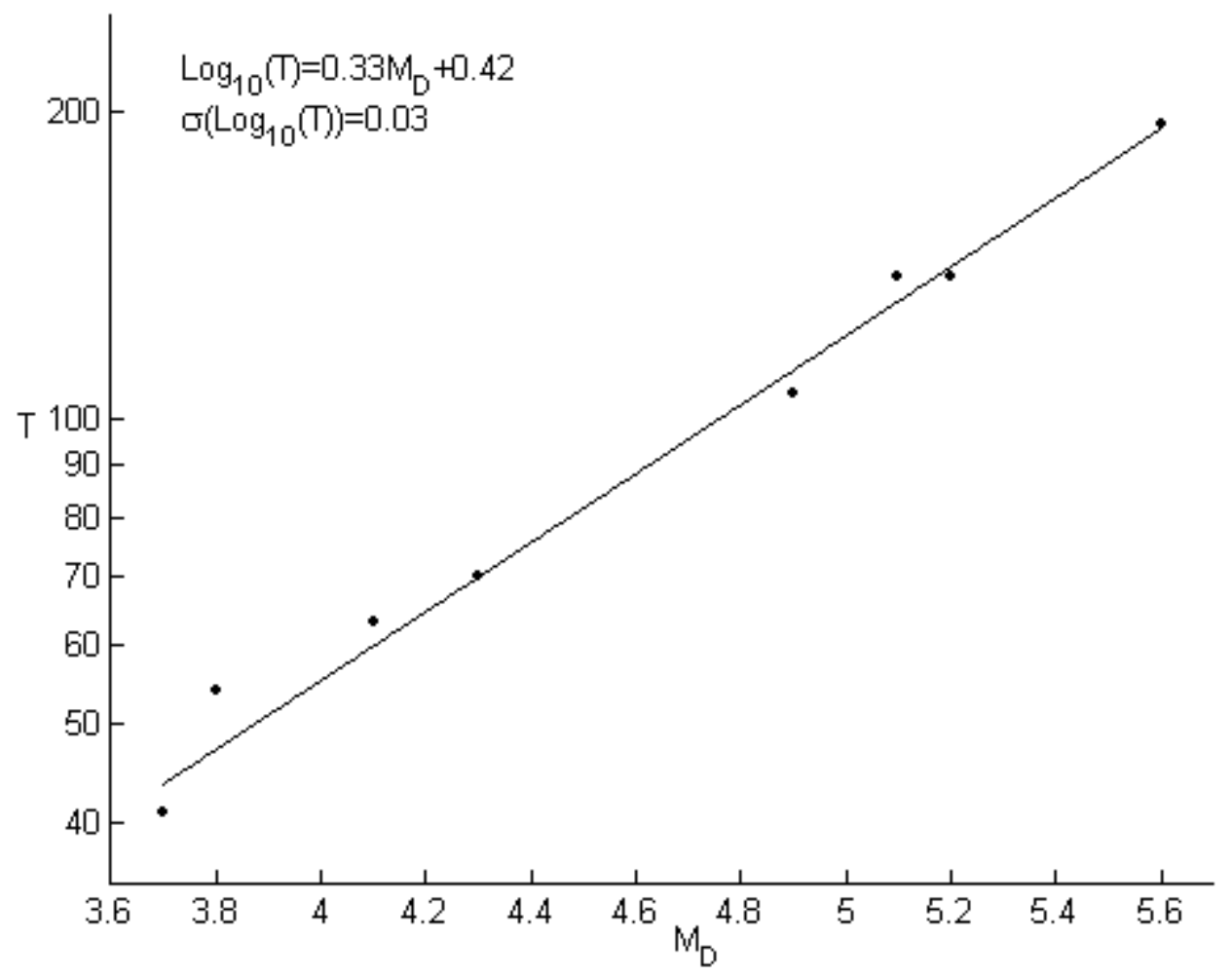

(b)

Fig. 2 


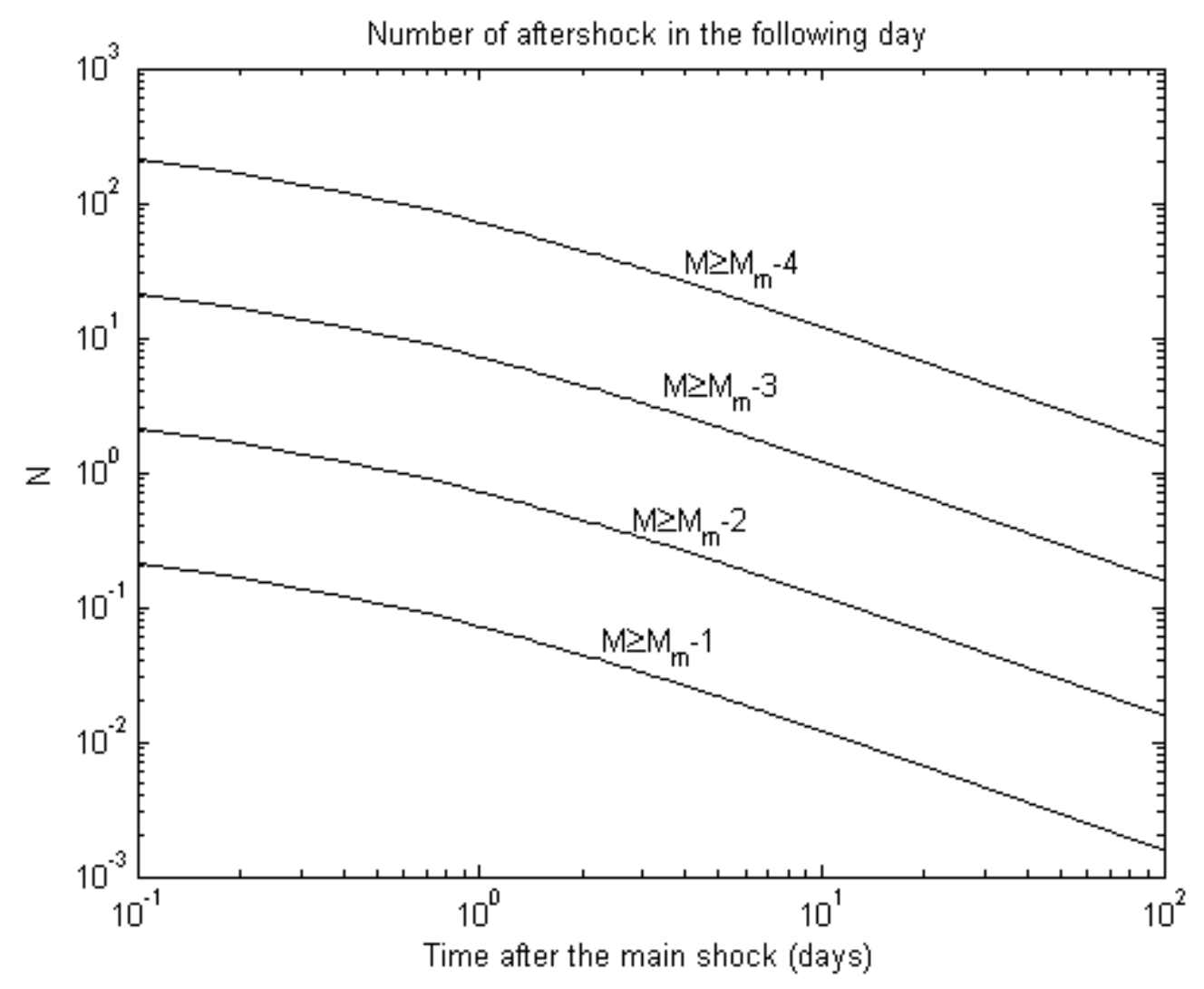

Fig. 3

Probability of aftershock with $M \geq M_{m}-1$

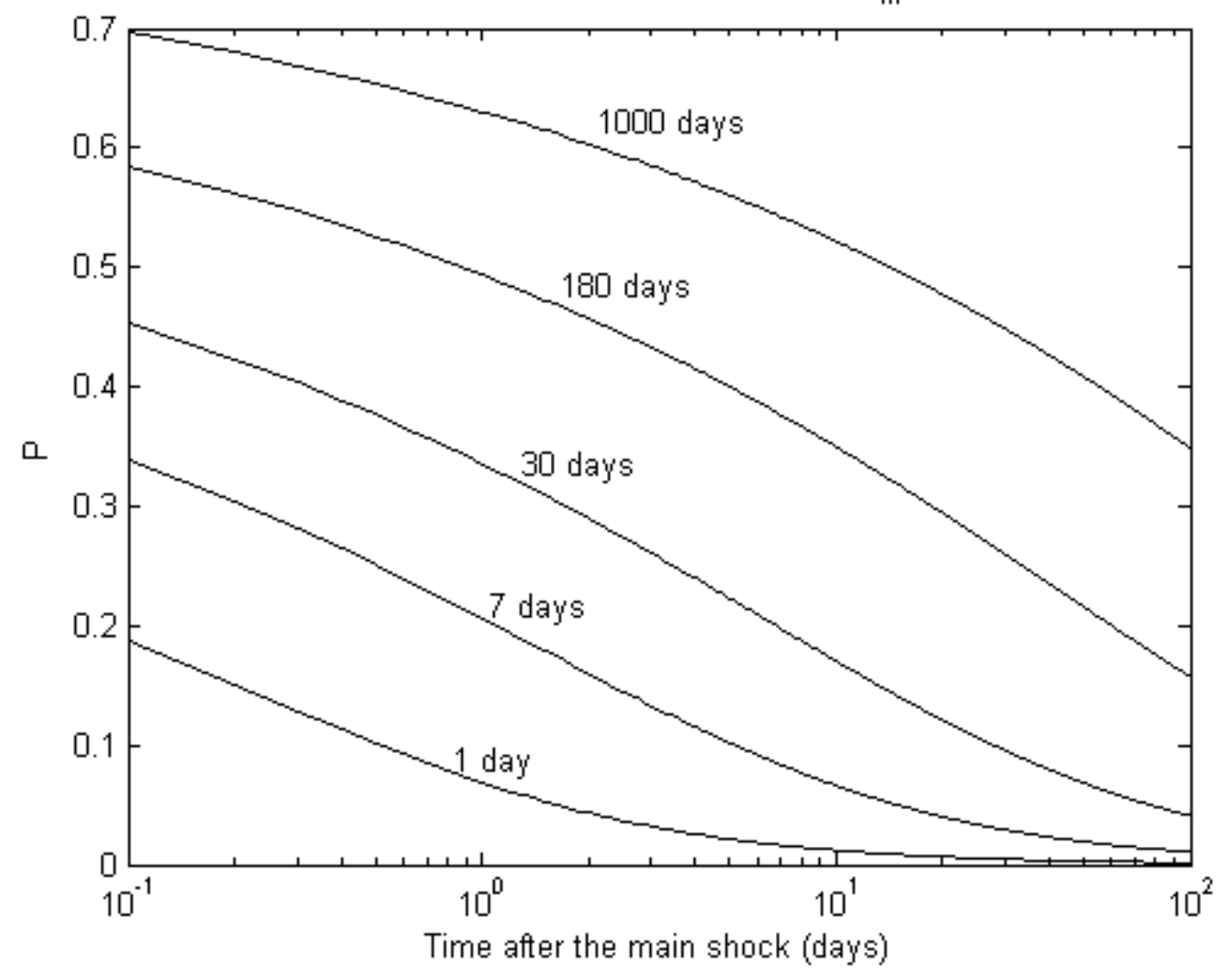

Fig. 4 


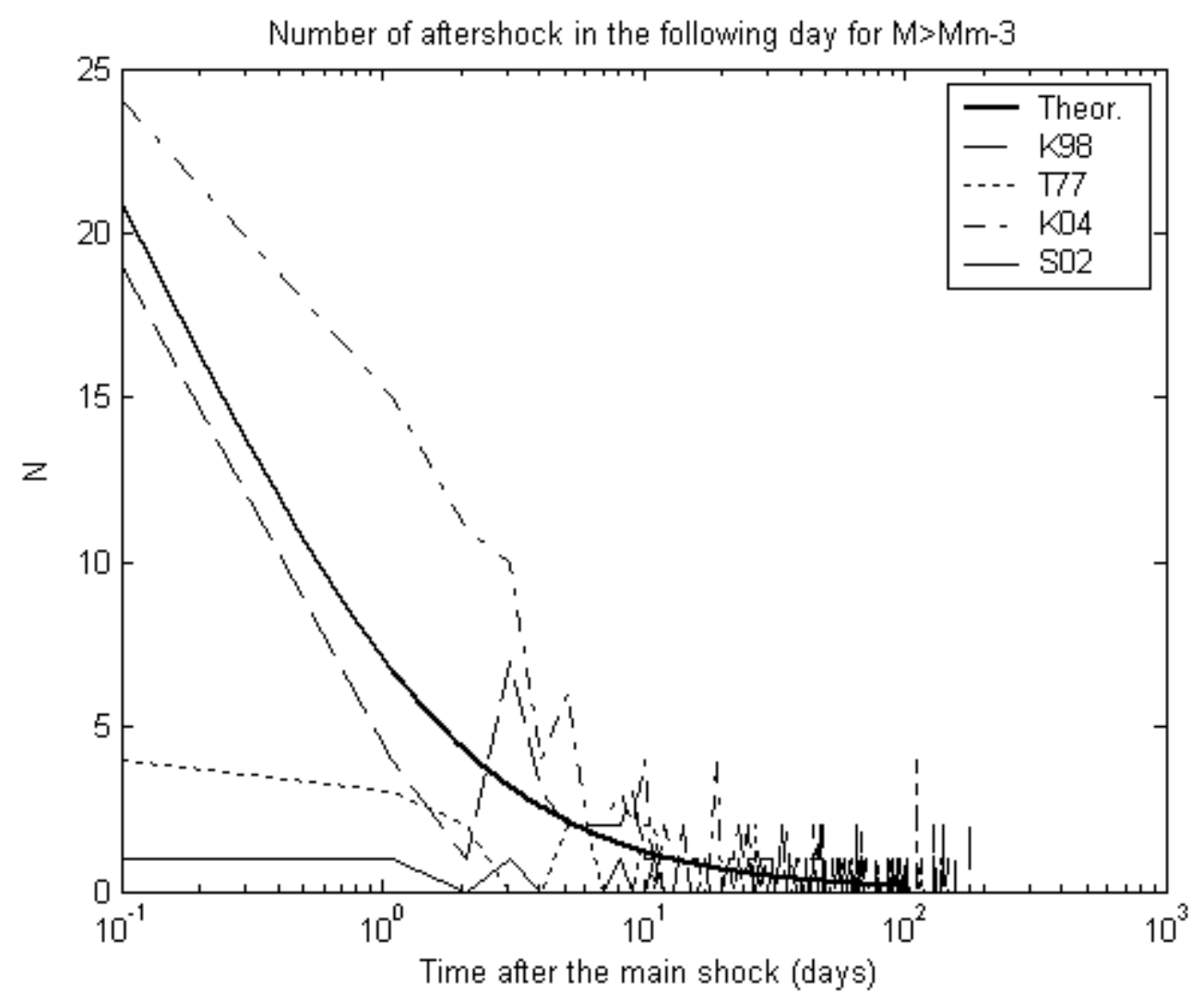

Fig. 5

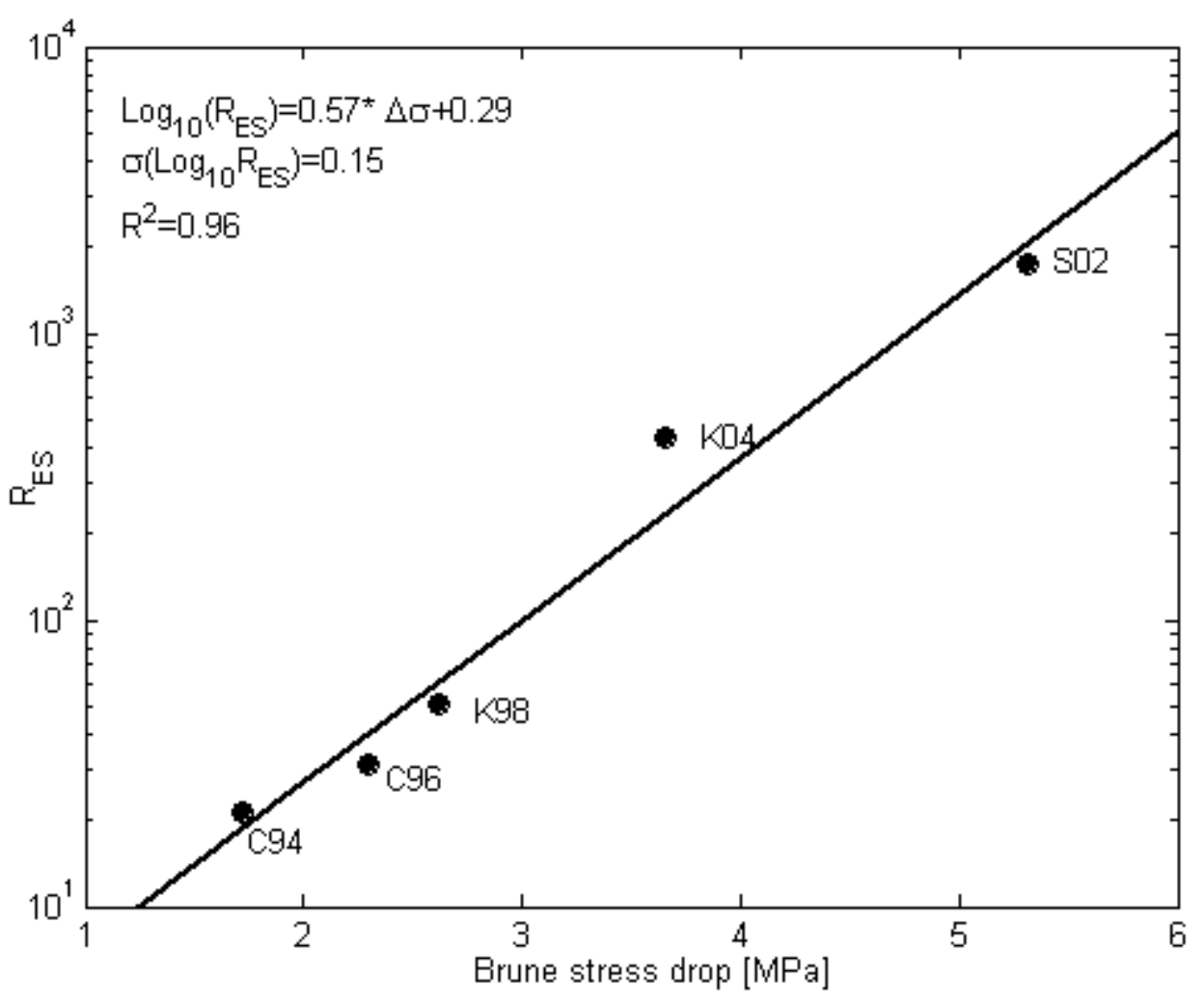

Fig. 6 


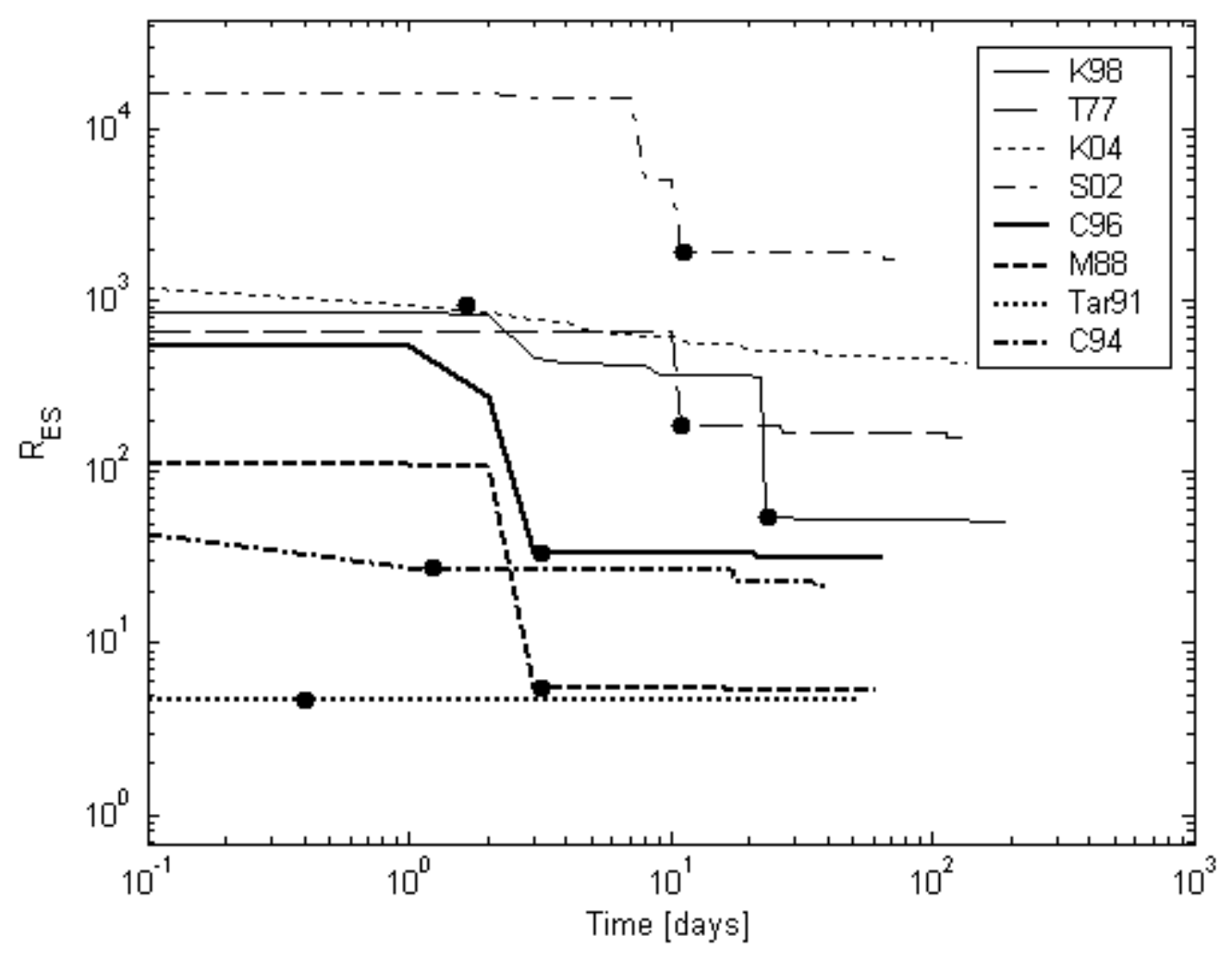

Fig. 7

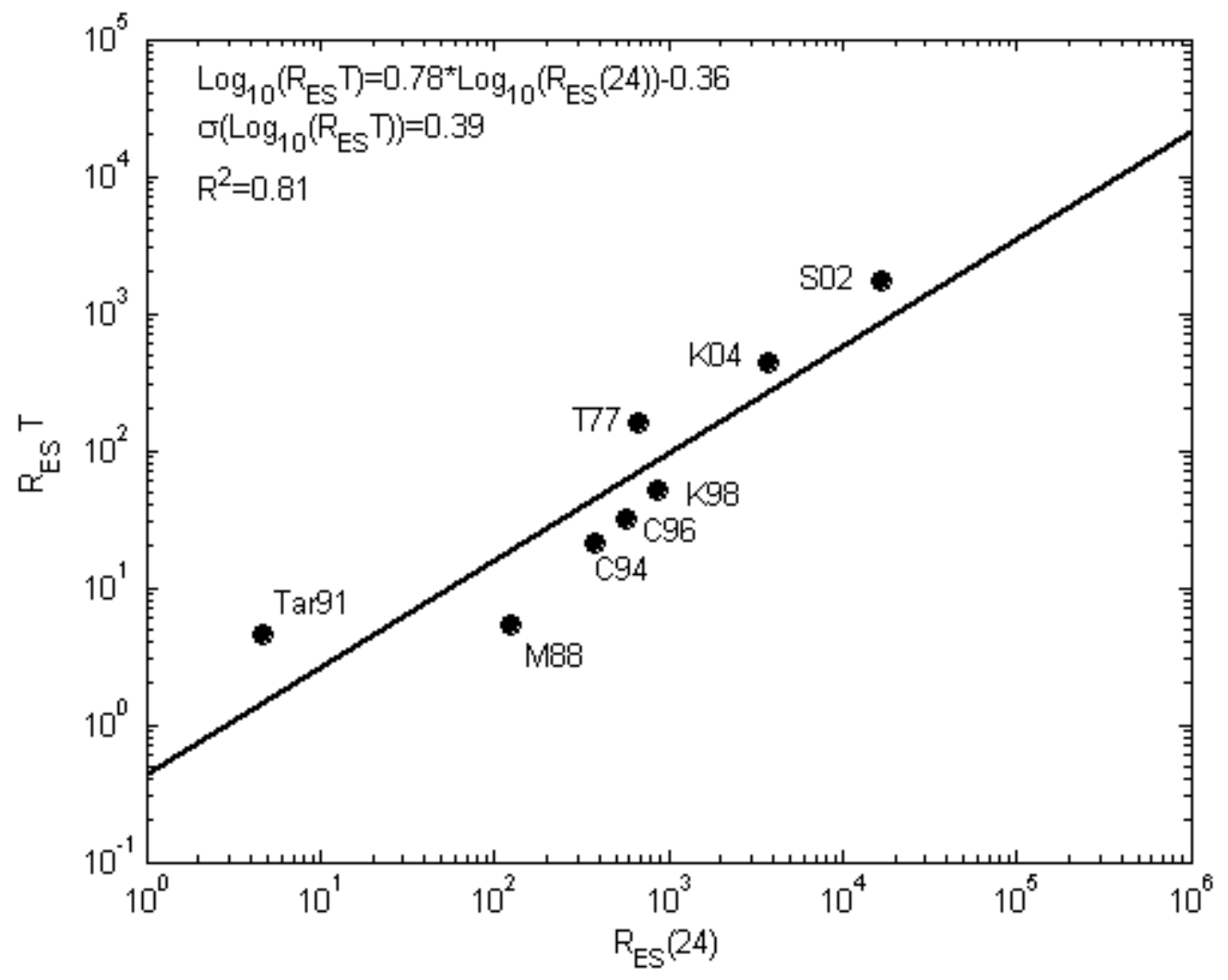

Fig. 8 


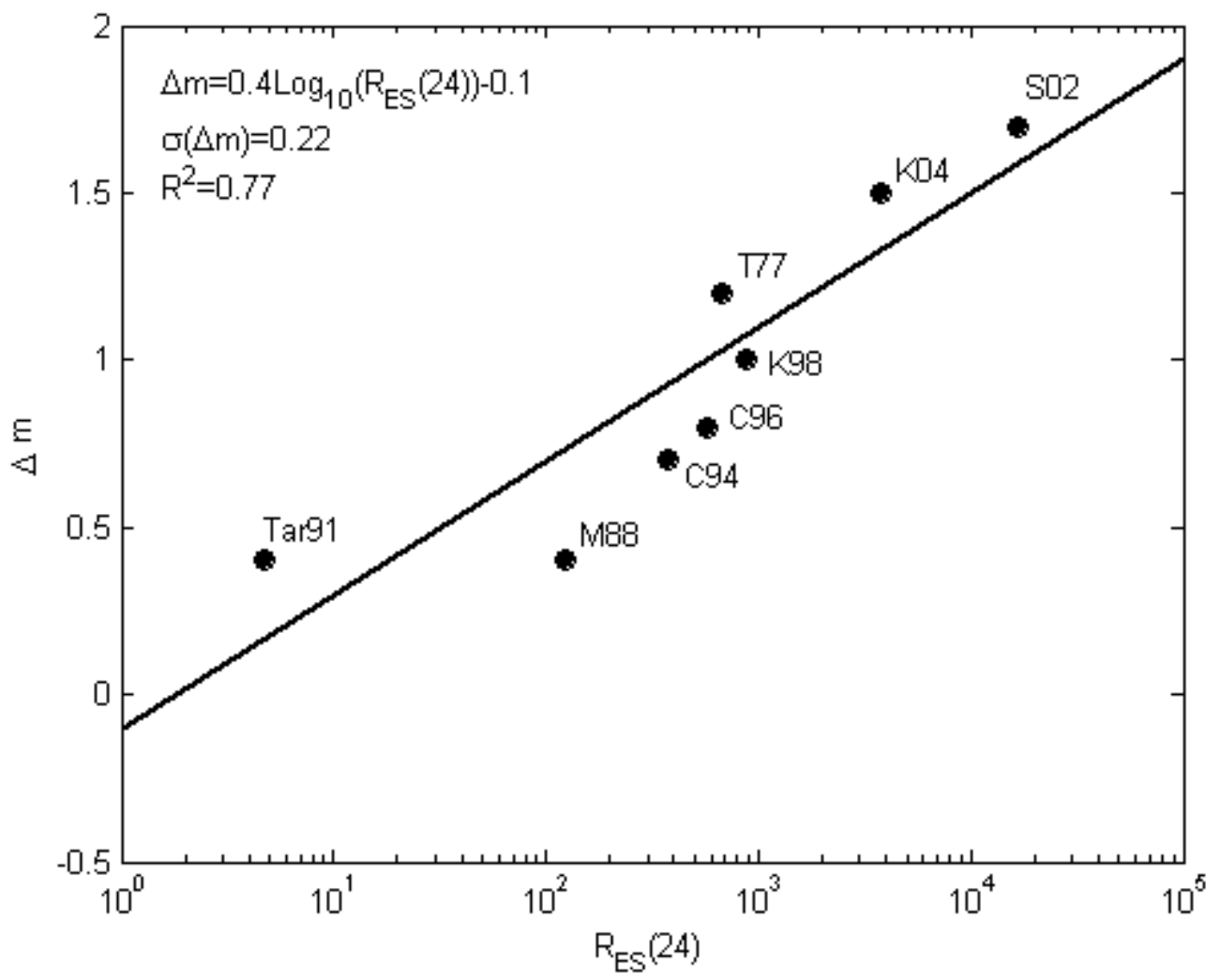

Fig. 9 